\title{
AS INCERTEZAS CIENTÍFICAS E A TEORIA DA PROBABILIDADE NA DECISÃO JUDICIAL: O CASO DO BISFENOL A - BPA NAS EMBALAGENS PLÁSTICAS
}

\author{
UNCERTAINTIES SCIENTIFIC AND PROBABILITY THEORY IN JUDICIAL \\ DECISION: THE CASE OF BISPHENOL A - BPA IN CONTAINERS PLASTIC
}

\author{
${ }^{1}$ Graziela de Oliveira Kohler
}

\section{RESUMO}

O presente trabalho pretende, a partir da matriz pragmático-sistêmica, observar a teoria da probabilidade como apoio decisional aos casos que envolvem incertezas cientificas. A toxidade dos componentes químicos nas embalagens plásticas em contato com os alimentos é objeto de estudo nos mais variados campos do saber, sendo o componente químico bisfenol A (BPA) apontado como maléfico à saúde humana. As embalagens possuem uma função socioeconômica de extrema importância, mas a inobservância de limites mínimos na produção e informação aos consumidores pode gerar riscos complexos e invisíveis. O trabalho realiza uma conexão entre essas incertezas e a comunicação da decisão jurídica.

Palavras-chave: Plásticos, riscos, Decisão jurídica, Teoria da probabilidade

\begin{abstract}
This paper aims at observing the theory of probability as decisional support to cases involving scientific uncertainties, from the pragmatic-systemic matrix. The toxicity of chemicals in packaging plastic in contact with food is an object of study in various area of knowledge, and the chemical compound Bisphenol A (BPA) appointed as harmful to human health. The packages have an important socio-economic function, but failure to comply with minimum limits on production and consumer information can generate complex and invisible risks. The paper makes a connection between the scientific uncertainties and communication of legal decision.
\end{abstract}

Keywords: Plastics, risks, Legal decision, Probability theory

\footnotetext{
${ }^{1}$ Doutoranda em Direito pela Universidade do Vale do Rio dos Sinos - UNISINOS, Rio Grande do Sul (Brasil). Professor de Direito pela Faculdade da Serra Gaúcha - FSG, Rio Grande do Sul (Brasil).

E-mail: grazielak@ superig.com.br
} 


\section{Introdução}

Os materiais plásticos são encontrados em praticamente todo o ambiente que nos rodeia, estão presentes nos carros, nos móveis, nos computadores, nos eletrodomésticos, nos calçados, na construção civil, etc. São produzidos por subsistemas organizacionais que movimentam a economia e geram milhares de empregos. Parte do sucesso desses materiais está no fato de possibilitar soluções de menor custo para problemas tecnológicos e sociais relevantes. O plástico surgiu como contribuição à qualidade de vida humana, e com isso, a cadeia produtiva desses materiais alcançou importância socioeconômica no Brasil e no mundo.

No entanto, estudos científicos apontam que a utilização desses materiais quando em contato com alimentos pode gerar riscos de danos à saúde humana. Um componente químico denominado de bisfenol A (BPA), sintetizado pelo homem, é utilizado na produção de materiais em policarbonato e nas resinas epóxi. O policarbonato é aplicado na fabricação de embalagens para alimentos e bebidas, a exemplo de jarros de plástico, copos, tigelas, mamadeiras de crianças, etc.

Pesquisas sinalizam que o BPA possui um grau de toxidade, apontando-o como estrogênio sintético, desregulador endócrino e também cancerígeno. Entretanto, não há certezas científicos sobre os efeitos tóxicos ao organismo humano e suas consequências. Em contrapartida, através do princípio da precaução, vários países proibiram a venda e circulação de mamadeiras produzidas à base de policarbonato, uma vez que há riscos de graves prejuízos aos órgãos reprodutivos das crianças.

Diante desses riscos, o Ministério Público Federal ingressou com uma ação civil pública contra a ANVISA para obter a obrigação de fazer por parte dessa, para que regulamente a obrigatoriedade aos fabricantes em informar nos rótulos e embalagens acerca dos riscos que os consumidores estão predispostos com a utilização do BPA. A decisão jurídica passa a ser complexa e contingente, mas de qualquer modo, ressoará em outros sistemas.

Com isso, justifica-se o objetivo do presente trabalho em observar o binômio entre a comunicação da decisão jurídica e os riscos de danos futuros com o uso de embalagens plásticas em contato com alimentos. Para tanto, o trabalho pretende responder ao seguinte questionamento: O julgador pode utilizar a probabilidade como redução da complexidade nos casos de incertezas científicas? Quais os parâmetros da teoria das probabilidades na 
decisão jurídica? O método-base utilizado para a pesquisa é o sistêmico, tendo em vista que permite a observação da sociedade hipercomplexa. Ainda, o referido método foi eleito porque consegue adaptar os sistemas sociais à lógica dos riscos e das incertezas científicas.

Isso posto, o trabalho foi estruturado em três itens: o primeiro, aborda o os subsistemas das indústrias produtoras de embalagens plásticas em contato com alimentos; o segundo, destina-se ao processo judicial movido pelo Ministério Público Federal contra a Anvisa acerca do BPA; e o terceiro, trabalha a utilização da probabilidade nas decisões judciais.

\section{Os subsistemas das indústrias produtoras de embalagens plásticas em contato com alimentos}

Os plásticos percorrem por diferentes subsistemas, são utilizados em construções, na medicina, em materiais esportivos, nos transportes, na agricultura, etc. No entanto, o maior consumo de plásticos é no setor de embalagens, que é responsável por cerca de $40 \%$ do material produzido no mundo. (PLASTICS EUROPE)

As embalagens plásticas são de grande utilidade para o acondicionamento e distribuição de produtos. Diante versatilidade e flexibilidade das propriedades dos materiais plásticos, as indústrias observaram um nicho de possibilidades mercadológicas para as embalagens. Essa forma de recipiente entrou no mercado como uma opção prática e econômica para o armazenamento e transporte das mais variadas espécies de produtos, pois o embalamento é essencial para a integridade de qualquer produto, seja ele orgânico ou inorgânico. (MAGRINI et al, 2013, p. 31)

Nessa ótica, Magrini e outros (2013, p. 31) entendem que "as embalagens apresentam funções de contenção, proteção, utilidade e comunicação". Além de proteger os produtos das influencias do ambiente, as embalagens podem comunicar informações relevantes aos consumidores, como a identificação do fabricante, do produto, dos ingredientes e dos cuidados necessários para a devida manipulação. Ainda, os plásticos transparentes permitem a visualização dos produtos, a exemplo dos filmes de PVC utilizados para embalar as bandejas de carne.

Com isso, o setor alimentício obteve a possibilidade de otimizar o processo de armazenamento e distribuição de seus produtos, diminuindo os custos e mantendo a integridade dos alimentos. Segundo Barros (2010, p. 19): 


\begin{abstract}
Uma das principais funções da embalagem é proporcionar ao consumidor um alimento com o mesmo nível de qualidade dos produtos frescos ou recémpreparados, devido à sua capacidade de protegê-lo contra agentes deteriorantes, infectantes e sujidades. A embalagem atua como uma barreira de proteção para o alimento, impedindo o contato direto com o ambiente, evitando contaminações, manuseio inadequado, falta de higiene, perda de seus constituintes e de suas características próprias.
\end{abstract}

As embalagens visam a proteção do alimento em relação à ação do ambiente, auxiliando na conservação durante o período de comercialização, que inicia na produção e termina ao tempo do consumo. Do contrário, a ausência de embalagens deixaria os alimentos sujeitos à contaminação e rápida deterioração. Atualmente, a maioria dos alimentos e bebidas que circulam no mercado de consumo são armazenados em recipientes produzidos a partir de materiais plásticos. Cabendo a cada organização escolher o a especificidade do material empregado e a técnica adequada para a destinação de cada produto. (BARROS, 2010, p. 19)

As embalagens devem ser escolhidas através de critérios bem definidos pelas organizações, pois esses recipientes são dotados de capacidades químicas passíveis de influenciar nas propriedades dos alimentos, podendo torna-los impróprios ao consumo. De acordo com Selke (2003, p. 140), as embalagens de plástico têm grande margem de contribuição para as atividades humanas, mas há percepções negativas dos consumidores que vão desde a crença de que todos os plásticos são associados a emissões perigosas, como a migração dos plastificantes aos alimentos, o que pode causar danos à saúde humana.

Sobre isso, Barros (2010, p. 21) dá conta de que:

O principal fator responsável pela mudança dessas características é a migração dos componentes de baixo peso molecular do material da embalagem para o alimento. A preocupação essencial quanto à seleção e ao uso de materiais de embalagem está, portanto, relacionada com a migração de componentes do material de embalagem que, ainda que não seja necessariamente danosa à saúde do homem, pode prejudicar a qualidade do alimento.

Com isso, torna-se possível compreender que são acrescidos aditivos e plastificantes aos materiais plásticos para que se obtenha um melhoramento no processamento das embalagens. Essas substâncias, diante do baixo peso molecular, podem se desprender dos recipientes e migrar para o alimento ali guardado. São dotadas de um certo grau de risco quando em contato com os alimentos, pois há a possibilidade de migração de componentes considerados tóxicos ao organismo humano, bem como a possibilidade de transpor riscos ao meio ambiente.

O interesse público é de extrema relevância nesses casos, tanto que organizações governamentais são destinadas à elaboração de regulamentos técnicos, inclusive com a 
definição de critérios gerais e específicos a serem observados no processo industrial. Como estão diretamente relacionadas à segurança alimentar, a Anvisa possui competência para regulamentar, controlar e fiscalizar esses recipientes destinados ao contato com alimentos. São regulamentados através de resoluções da Diretoria Colegiada da Agencia Nacional de Vigilância Sanitária (ANVISA), as quais estão compatibilizadas com as resoluções GMC MERCOSUL.

O artigo $8^{\circ}$ da Lei n. 9782/99 que define o Sistema Nacional de Vigilância Sanitária, dispõe que os "alimentos, inclusive bebidas, águas envasadas, seus insumos, suas embalagens, aditivos alimentares, limites de contaminantes orgânicos, resíduos de agrotóxicos e de medicamentos veterinários" são submetidos ao controle do referido órgão. De modo geral, todas as indústrias que fabricam embalagens em contato com alimentos, tanto de materiais plásticos, vidros, metais, ceras, ceramidas, dentre outros, estão submetidas às portarias e resoluções emitidas pela ANVISA, ordenadamente, elaboradas de acordo com cada categoria de produtos.

Com relação às embalagens plásticas, a ANVISA conta com uma portaria e mais oito resoluções em vigor. São elas:

Portaria ${ }^{\circ}$ 987, de 8 de dezembro de 1998. Aprova o Regulamento Técnico para embalagens descartáveis de polietileno tereftalato - PET - multicamada destinadas ao acondicionamento de bebidas não alcóolicas carbonatadas.

Resolução $\mathrm{n}^{\circ} 105$, de 19 de maio de 1999. Aprova o Regulamento Técnico Disposições Gerais para Embalagens e Equipamentos Plásticos em contato com Alimentos.

Resolução no 124, de 19 de junho de 2001. Aprova o Regulamento Técnico sobre Preparados Formadores de Películas a base de Polímeros e/ou Resinas destinados ao revestimento de Alimentos.

Resolução $\mathrm{n}^{\circ}$ 146, de 06 de agosto de 2001. Aprova o processo de deposição de camada interna de carbono amorfo em garrafas de polietileno tereftalato (PET) virgem via plasma, destinadas a entrar em contato com alimentos dos tipos de I e VI, da temperatura de congelamento à temperatura ambiente por tempo prolongado, e temperatura máxima de processamento do alimento de $121^{\circ} \mathrm{C}$.

Resolução RDC no 20, de 26 de março de 2008. Aprova o Regulamento Técnico que dispõe sobre o Regulamento Técnico sobre embalagens de polietilenotereftalato (PET) pós-consumo reciclado grau alimentício (PET-PCR grau alimentício) destinados a entrar em contato com alimentos.

Resolução RDC no 51 , de 26 de novembro de 2010. Dispõe sobre migração em materiais, embalagens e equipamentos plásticos destinados a entrar em contato com alimentos.

Resolução RDC $n^{\circ} 52$, de 26 de novembro de 2010. Dispõe sobre corantes em embalagens e equipamentos plásticos destinados a estar em contato com alimentos.

Resolução RDC n ${ }^{\circ} 56$, de 16 de novembro de 2012. Dispõe sobre a lista positiva de monômeros, outras substâncias iniciadoras e polímeros autorizados para a elaboração de embalagens e equipamentos plásticos em contato com alimentos. Resolução RDC $\mathrm{n}^{\circ} 17$, de 12 de janeiro de 2008. Dispõe sobre Regulamento 
Técnico sobre Lista Positiva de Aditivos para Materiais Plásticos destinados à Elaboração de Embalagens e Equipamentos em Contato com Alimentos.

Nesse ponto, cabe ressaltar que as normas da ANVISA estão de acordo com os regulamentos técnicos adotados pelo Mercosul. As bases de suas construções estão em estudos e regulamentos provenientes da Comunidade Européia, do Food and Drug Administration (FDA) dos Estados Unidos da América e do Instituto Alemão de Avaliação de Risco (BFR).

A RDC n 91/2001 da ANVISA, define embalagens para alimentos como "o artigo que está em contato direto com alimentos, destinado a contê-los, desde a sua fabricação até a sua entrega ao consumidor, com a finalidade de protegê-los de agente externos, de alterações e de contaminações, assim como de adulterações". O item 3 dessa resolução trata da migração de componentes dos materiais da embalagem para os alimentos, uma vez que essa transferência pode ocorrer devido a fenômenos físicos químicos.

Referido órgão tem o papel de acompanhar e combater causas que aludam riscos de danos à saúde. E é exatamente por esse motivo que o Ministério Público ingressou com uma ação civil pública contra a ANVISA a respeito do componente químico encontrado em algumas embalagens, chamado de Bisfenol A, conforme abordado a seguir.

\section{Da ação civil pública envolvendo o Bisfenol A - BPA}

O Bisfenol A - BPA, representado pela composição 2,2 -bis (4 -hidroxifenil) propano, é um componente químico utilizado na fabricação de alguns materiais plásticos, em especial, nos policarbonatos e nas resinas epóxi. Essa substância é objeto de pesquisas científicas desde a década de 1980, em que pesquisadores alertam sobre os seus riscos em relação à saúde humana e ao meio ambiente. Dentre as pesquisas realizadas, o BPA é apontado como estrogênio sintético, desregulador endócrino e cancerígeno.

Magrini et al (2012, p. 140) esclarecem que "no final de 2004, 31 trabalhos publicados na literatura técnica relativa aos efeitos adversos do BPA em doses iguais ou inferiores a atual dose de referência da EPA.” Esses trabalhos traduzem estudos em animais, onde foram observados o seguinte: início precoce de maturação sexual; níveis de hormônio luteinizante do plasma alterados e diminuição da testosterona plástica em machos; tamanho da próstata aumentada em prole masculina; diminuição na produção de esperma e da 
fertilidade em machos; estimulação de glândulas mamarias em prole do sexo feminino; aumento de mortalidade de embriões.

Diante dos riscos apresentados, o Ministério Público Federal ajuizou uma ação civil pública com pedido de antecipação dos efeitos da tutela contra a Agencia Nacional de Vigilância Sanitária (ANVISA), tombado sob o número 0001724-67.2011.4.03.6100, em trâmite na $13^{\mathrm{a}}$ Vara da seção judiciária de São Paulo/Justiça Federal. A ação proposta intenta que seja determinado à ANVISA que regulamente o dever de informar dos fabricantes de produtos plásticos sobre a presença de bisfenol A - BPA nos produtos postos em circulação. Diante o artigo $9^{\circ}$ do Código de Defesa do Consumidor ${ }^{1}$, o pedido contemplou a obrigatoriedade de informações de maneira adequada e ostensiva nas embalagens dos produtos. Tal medida, busca garantir o direito fundamental à saúde e a devida informação aos consumidores.

O magistrado da $13^{\mathrm{a}}$ Vara da seção judiciária de São Paulo/Justiça Federal deferiu o pedido liminar e fixou multa diária no valor de $\mathrm{R} \$ 20.000,00$ (vinte mil reais) no caso de descumprimento da obrigação de fazer. Inconformada, a ANVISA interpôs agravo de instrumento de número 0011173-16.2011.4.03.0000/SP, de relatoria do Desembargador Federal Nery Junior, que foi provido para reformar a decisão de primeiro grau. ${ }^{2}$

\footnotetext{
1 “Art. $9^{\circ}$. O fornecedor de produtos e serviços potencialmente nocivos ou perigosos à saúde ou segurança deverá informar, de maneira ostensiva e adequada, a respeito da sua nocividade ou periculosidade, sem prejuízo da adoção de outras medidas cabíveis em cada caso concreto."

${ }^{2}$ AGRAVO DE INSTRUMENTO - AÇÃO CIVIL PÚBLICA - ANTECIPAÇÃO DA TUTELA - ART. 273, CPC - PROVA INEQUÍVOCA - VEROSSIMILHANÇA DA ALEGAÇÃO - FUNDADO RECEIO DE DANO IRREPARÁVEL OU DE DIFÍCIL REPARAÇÃO - AUSÊNCIA DOS REQUISITOS - RECURSO PROVIDO. 1. Para a concessão de tutela antecipada, revela-se imprescindível prova inequívoca e verossimilhança do alegado, havendo fundado receio de dano irreparável ou de difícil reparação e ou que fique caracterizado o abuso do direito de defesa ou manifesto propósito protelatório. 2. A verossimilhança é o pressuposto que se refere à alegação do direito do demandante e a prova inequívoca pertine à documentação acostada e que deverá ser analisada a fim de caracterizar a probabilidade daquilo que foi alegado. Trata-se de um Juízo provável sobre o direito do autor, é o fumus boni iuris. 2. Faz-se mister, ainda, verificar a presença de fundado receio de dano irreparável ou de difícil reparação (periculum in mora). 3. Não se vislumbra, portanto, a verossimilhança necessária da alegação para validar a antecipação dos efeitos da tutela, nos termos do ar. 273, CPC. 4. Ainda que vencida a ausência supracitada e adotadas como verdadeiras todas as suposições aventadas na exordial, não se verifica o fundado receio de dano irreparável ou de difícil reparação, posto que a ora agravante, na qualidade de promotora da proteção da saúde da população através do controle sanitário da produção e da comercialização de serviços, atenta à "tendência" mundial com relação ao tema, vem fomentando o debate e a regulamentação do uso do BISFENOL -A no país. Aliás, as medidas adotadas pela Agência tomam contornos internacionais, abraçando e uniformizando, as regras para os países componentes do Mercosul. 5. Assim, qualquer alteração imposta - em caráter liminar - pelo Poder Judiciário, além de ser dotada de precariedade, poderia desestruturar a atual regulamentação entre os paises do Mercado Comum do Sul. 6. Já existe em vigor normas regulamentadoras do uso da substância em questão em embalagens e utensílios, limitando sua aplicação segundo o LME de 0,6 mg/kg, nos termos da Resolução RDC 17, de 17/3/2008. 7. Ainda que a medida deferida tenha sido tão somente a regulamentação da obrigatoriedade para os fabricantes da informação, ostensiva e adequada, quanto à presença da substancia "Bisfenol A (BPA)" nas embalagens e rótulos de produtos que a contenham, importante ressaltar que tal informação, ao invés de orientar os consumidores, poderá confundi-los, tendo em vista a porcentagem mínima desses que tem acesso às informações da eventual toxicidade da
} 
A ação foi julgada improcedente, sob o argumento decisional de que não há demonstração inequívoca de potencialidade ou perigo à saúde, uma vez que a ANVISA estabelece, através da Resolução RDC 17, de 17.03.2008, o limite de 0,6 mg de Bisfenol a/Kg de alimento. Ainda, com base em depoimento da testemunha arrolada pelo Ministério Público Federal, o julgador entendeu que a nocividade apontada na ação é reportada a estudos ainda não concluídos.

Da fundamentação da decisão mencionada, extrai-se:

\begin{abstract}
O pedido deduzido pelo parquet não merece acolhida.O artigo $99^{\circ}$, da Lei $n$. 8.078/90 (Código de Defesa do Consumidor), ao tratar da necessidade de se fazer inserir no corpo dos produtos ou serviços advertência quanto aos perigos à saúde ou a segurança, assim disciplina a questão, verbis:"Art. 9. ${ }^{\circ}$. O fornecedor de produtos e serviços potencialmente nocivos ou perigosos à saúde ou segurança deverá informar, de maneira ostensiva e adequada, a respeito de sua nocividade ou periculosidade, sem prejuízo da adoção de outras medidas cabíveis em cada caso concreto".O que se extrai da leitura do mencionado dispositivo legal é a necessidade de existir, previamente demonstrada, a potencialidade nociva ou perigosa aí definida.No caso concreto não há essa demonstração inequívoca de que a presença do BISFENOL $\mathrm{A}$ em produtos que atendam à exigência posta pela ANVISA tenha esse potencial nocivo ou perigoso à saúde ou à segurança.Ademais, como esclarece a ANVISA, o uso dessa substância já é regulamentado por meio da Resolução RDC n. ${ }^{\circ}$ 105, de 19.05.1999 e da Resolução RDC 17, de 17.03.2008, estabelecido como Limite de Migração Específica (LME) a fração de 0,6 mg de Bisfenol $\mathrm{A} / \mathrm{Kg}$ de alimento.A Agência, portanto, não está omissa quanto ao tema levantado na presente ação civil pública, não se justificando, pelos elementos contidos na lide, providência meramente ilustrativa sobre a presença ou não dessa substância em determinadas embalagens.Ademais, a testemunha ouvida em Juízo, arrolada pelo Ministério Público Federal, não esclarece, de modo peremptório, eventuais efeitos nocivos do BPA nos índices fixados pela ANVISA, reportando-se a estudos ainda não concluídos, afirmando-se que "estão em curso estudos sobre o tema mas oficialmente os dados ainda não foram divulgados"
\end{abstract}

Da sentença, foi interposta a devida apelação civil, que até o momento não foi julgada. Cabe mencionar que após a interposição da presente demanda, a ANVISA regulou acerca da proibição de mamadeiras em policarbonato no território nacional, seguindo o caminho das regulamentações de outros países. ${ }^{3}$

Nesse contexto, torna-se possível observar que há riscos de danos refletidos no futuro, o qual torna-se depende de uma decisão jurídica, ou seja, o processo de decidir, de

substância. E vale lembrar, que esta porcentagem mínima de consumidores (bem como os demais que sequer avistam o problema), em relação a sua saúde, estão resguardados pela regulamentação expendida pela ANVISA, consistente na limitação da migração do BISFENOL. 8. Não vislumbrando os pressupostos autorizadores do art. 273, CPC, necessária a reforma da decisão agravada. 9. Agravo de instrumento provido. Terceira Turma do TRF3. AI - AGRAVO DE INSTRUMENTO. Proc. N. 0011173-16.2011.4.03.0000. Relator DESEMBARGADOR FEDERAL NERY JUNIOR. Julgado em 15/09/2011. Publicado em e-DJF3 Judicial 1 DATA: 23/09/2011, p. 540.

${ }^{2}$ Sentença disponibilizada no D.Eletrônico de sentença em 28/02/2013 ,p. 126.

${ }^{3} \mathrm{Na}$ resolução RDC n. 41, de 16 de setembro 2011, foi proibido o de uso de bisfenol A na fabricação e importação de mamadeiras destinadas a alimentação de lactentes. O artigo $1^{\circ}$ estabelece: "Fica proibida a fabricação e importação de mamadeiras para a alimentação de lactentes que contenham a substância bisfenol A [2,2-bis(4-hidroxifenil) propano, CAS 000080-05-7] na sua composição.” 
alguma forma, também se transforma em risco. E é justamente no âmbito das decisões dos sistemas que as complexidades e contingências se alargam continuamente. Com isso os potenciais de decisão também são ampliados, pois através da noção de risco, um observador de segunda ordem detém a possibilidade de prevenir danos. (Luhmann, 1992, p. 34)

Rocha e Duarte (2012, p. 19) explicam que:

$\mathrm{O}$ direito tem que fazer com que aqueles instantes, aquelas possibilidades de construção e de decisão realizadas pela sociedade, tenham duração, sejam assimiladas, institucionalizadas. Isto é, o Direito tem de fazer com que a sociedade exista, haja vista que é ele quem constrói a sociedade. Nesse sentido, o Direito é um dos construtores da sociedade, de instituições, ou seja, de decisões, de valores, de experiências, de desejos, de atos, de situações que se deseja a perpetuação, manutenção, institucionalização. Assim, o Direito tem, na realidade, a função de institucionalizar a sociedade.

E justamente nesse ponto que a decisão judicial deve atender a realidade dos riscos, não somente com a responsabilidade sobre o que ressoa nos demais subsistemas sociais, mas também incluir mecanismos que possam aliar os riscos ao alcance do futuro. Dessa forma, a pesquisa destina a relativização das certezas para critérios de alta probabilidade como elementos da decisão judicial, conforme passa a expor.

\section{A probabilidade como elemento da decisão judicial.}

A sociedade de risco instaurou uma crise na segurança jurídica, enfraquecendo as noções de certeza e de provas causais. O risco passa a ser observado como um paradoxo que gera irritabilidade nas demandas judiciais, um paradoxo que causa angústia ao observador e que pode gerar resultados vagos e confusos. A não observação ou a omissão do paradoxo também pode paralisar o observador, obstaculizando o desenvolvimento adequado da decisão judicial. Com isto, há a necessidade de articular mecanismos para atenuar esse paradoxo

Com efeito, a tomada de uma decisão pode tentar antever ou prevenir acontecimentos futuros. Entretanto, não garante a previsão segura de todas as situações, pois o prognóstico realizado hoje pode não se configurar no futuro. Neste ponto, denota-se o papel do Direito na concepção do risco, pois aquele tende a buscar formas de prevenção de acontecimentos futuros com base em experiências passadas através de decisões presentes. ${ }^{4}$

\footnotetext{
${ }^{4}$ Segundo Luhmann: "la atribuición a la decisión debe satisfazer condiciones específicas; entre otras, la de que las alternativas se distingan reconociblemente en relación a la posibilidad de los daños. En el caso del riesgo, la atribuición las decisiones conduce a una serie de distinciones consecuentes, a una serie de bifurcacines (a un árbol de decisión), cada una de las cuales ofrece, a su vez, posibilidades de decisiones riesgosas". Luhmann, op. cit., 1992, p. 67.
} 
Os riscos podem ser minimizados através de uma decisão, seja ela judicial ou não. Segundo Rocha (2013, p. 37) "uma decisão sempre implica na possibilidade de que as suas consequências ocorram de maneira diferente". Segundo o autor, "cada vez que uma decisão é tomada em relação ao futuro (e sabemos que não é fácil tomá-la em razão da grande complexidade), temos que pensar na contingência (como sendo a possibilidade de que os fatos não ocorram da maneira como estamos antevendo)". Nesse passo, as decisões atuais tendem a buscar formas de prevenção de acontecimentos danosos no futuro.

O caso do uso do BPA nas embalagens plásticas em contato com alimentos demonstra uma crescente variação de possibilidades, as quais restam limitadas pelo conhecimento humano do tempo presente. Isso significa dizer que esse conhecer-saber pode vir a alcançar possibilidades diferentes das esperadas, motivo pelo qual é possível afirmar que o risco pode estar invisível, pois a confirmação ou não dos seus efeitos será revelado somente no futuro.

Nesse caso, estão envolvidos interesses difusos, que na concepção de Grinover (1984, p. 30), "trata-se de interesses espalhados e informais à tutela de necessidades, coletivas e de massa, comuns a um conjunto indeterminado e extremamente vasto de pessoas". Como esses interesses não trazem um sujeito individualizado e uma causa de pedir pessoal, o direito necessita se moldar a esse novo elemento.

Com efeito, diante dos riscos e dos interesses difusos, estão surgindo novas estratégias e novos modelos de pensamento jurídico, que têm o objetivo de superar os paradoxos decisionais, a fim de obter a prevenção ou precaução de eventos danosos. Na esfera do Direito ambiental, por exemplo, encontram-se defensores de novas teorias, como a tese da teoria das probabilidades para os casos de incertezas científicas e relativização das relações causais.

Diante das incertezas, a probabilidade ganha relevo em várias áreas do conhecimento, tanto que a Teoria das Probabilidades foi fundada por Pierre Simon Laplace na área da matemática, difundindo-se posteriormente na física, biologia, sociologia, etc. A probabilidade afasta a certeza absoluta e se transforma num juízo de quase-certeza.

Segundo Branco (1999, p. 42),

realmente, a certeza de um efeito parece ser meramente probalística. Tomemos como exemplo, o calor, gerando a ebulição da água. Ao aquecermos, em um recepiente, certo volume de água, temos a certeza antecipada de que o líquido será aquecido uniformemente (por causa das correntes de convecção) e que ao atingir aproximadamente $100^{\circ} \mathrm{C}$ (dependendo da pressão) entrará em ebulição. Não admitiremos previamente a hipótese de moléculas frias se separarem das quentes, formando blocos de gelo dentro da água fervente. Entretanto, tal probabilidade existe [...]. Essa probabilidade é tão pequena que, automaticamente, descartâmo-la 
de nossas considerações, ficando com a "certeza" do resultado de probabilidade maior.

Para esse autor, "a natureza probalística da certeza fica tanto mais evidente quanto mais distante estiver a causa do seu efeito final, como acontece nos sistemas complexos". (BRANCO, 1999, p. 42), E essa lógica passa a ter sentido no Direito, tendo em vista que a comunidade jurídica vem trabalhando na construção de novas teorias, na tentativa de reduzir a complexidade no tocante aos danos difusos e futuros.

No princípio da precaução, como demonstram Leite e Ayala (2004, p. 75), as bases de informação são precárias, pois as informações sobre a possibilidade de se concretizar um dano no futuro são incertas e insuficientes. Entretanto, esses autores entendem que "uma atuação precaucional exige a tomada de decisões ainda que o conhecimento disponível no momento não esteja em condições de permitir uma correta avaliação dos riscos, com a finalidade de justificar ou fundamentar as ações e medidas necessárias”.

Em que pesem os demais modelos jurídicos, há de ser dada relevância à Teoria das Probabilidades no Direito pátrio, o qual assinala a utilização de probabilidades nos casos de incertezas científicas. Tem-se que as organizações produtoras de embalagens envolvem conhecimentos científicos e tecnológicos que produzem dificuldades na identificação entre causas, danos e riscos. Muitas vezes, o conhecimento científico não conhece os resultados das tecnologias utilizadas, ou melhor, desconhece as consequencias que poderiam se concretizar, o que as tornariam meros indícios.

Nesse cenário, há uma incerteza científica que autoriza a flexibilização dos ditames de certeza para a observação da existência de probabilidades de danos no futuro. Nesse sentido, Díez-Picazo (1996, p. 238) entende que o juiz deve se contentar com a probabilidade de existência de relações causais, conjugando-o num fundamento racionalmente seguro. Sobre a teoria das probabilidades, ainda no âmbito do meio ambiente, Mirra (2001, p. 93) salienta que:

Comprovada, em termos de probabilidade, com elementos sérios e confiáveis, a realidade da degradação ambiental (efetiva ou potencial), ainda que sem certeza científica absoluta, o resultado da demanda deverá ser forçosamente o julgamento de procedência do pedido para o fim de impedir, fazer cessar ou reparar o dano e todas as consequiências prejudiciais do fato danoso.

Nesse passo, verifica-se que a probabilidade, desde que fundamentada adequadamente, autoriza o juiz a imputar obrigações ou responsabilidade aos envolvidos. Evidentemente, há uma dificuldade prática nessa teoria, pois a avaliação do grau de probabilidade também parte de complexidade e contingência. No entanto, torna-se um 
suplemento de argumentação para a decisão jurídica. Certamente, essa avaliação é realizada pelo magistrado, que terá o encargo de analisar se a probabilidade é consistente ou não.

Leite e Carvalho (2007, p. 89), parafraseando Lucia Gomis Catalá, descrevem:

\begin{abstract}
A partir da tensão entre os enfoques científico e jurídico, a causalidade deve restar comprovada quando os elementos apresentados levam a "um grau suficiente de probabilidade", a uma "alta probabilidade", ou, ainda, quando levam a uma probabilidade "próxima da certeza". Sensível à complexidade e às incertezas científicas, esta teoria estabelece que o legitimado ativo não estará obrigado a demonstrar essa relação de causa e conseqüência com exatidão científica. A configuração do nexo causal se dará sempre que o juiz obter a convicção de que existe uma "probabilidade determinante" ou "considerável".
\end{abstract}

Nesse viés, há várias opções suscitadas para auxiliar o julgador na observação do grau de probabilidade. Há quem entenda que deva ser realizada uma base em percentuais sobre a chance de o agente ter ocasionado o dano, ou ainda, o risco da ocorrência do dano. Nesse aspecto, verificado a probabilidade em $50 \%$, seria razão suficiente para a imputação. Por outro lado, há a perspectiva de adotar soluções como: alta probabilidade, mínima probabilidade ou alta improbabilidade. Ou, ainda, probabilidade decisiva ou preponderante ou qualificada. (REGAÑON; ALCALÁ, 2003).

De acordo com Carvalho (2013, p. 218),

A probabilidade pode ser avaliada quantitativa ou qualitativamente. A avaliação quantitativa da probabilidade é aquela que se reflete em números, por intermédio de percentuais, enquanto que a avaliação qualitativa se dá através de critérios de razoabilidade, em função da capacidade de antevisão. As probabilidades não quantificadas se exprimem a partir de ideia de verossimilhança, entendida como probabilidade não quantificada de que, no futuro, possam vir a ocorrer danos. ${ }^{5}$

Não obstante, a Teoria das Probabilidades não possui aplicação específica em nossos tribunais, uma vez que parte dos julgadores tem ainda um forte apego às ideias tradicionais de certeza e segurança jurídica. ${ }^{6}$ Evidentemente, os juristas ligados a dogmática tradicional enfrentam dificuldades em decidir com provas de probabilidades.

\footnotetext{
${ }^{5}$ Segundo esse autor (2013, p. 218), "ainda que incerto o futuro, a probabilidade consiste num fundamento racionalmente seguro, vez que, apesar da ficção operacional (descrição argumentativa do futuro), deve ser transparente quanto aos critérios analisados, de maneira controlada e não arbitrária. Sua utilidade singular consiste não em eliminar obscuridade do futuro, mas em fazer desta uma fonte produtiva de informações específicas".

${ }^{6}$ Exemplo de aplicação da teoria da probabilidade no Direito Ambiental: EMENTA: ação de indenização. Poluição ambiental. Agentes poluentes. Perícia. Nexo causal. Tendo a perícia comprovado o procedimento nocivo da ré, poluindo o meio ambiente com emissão de partículas diretamente e sem tratamento ao meio ambiente externo à empresa, de forma não compatível com as legislações que regem a matéria e que, por isso, advieram danos aos autores, assente a obrigação de indenizar. Quadro alérgico congênito. Não obstante a patologia da autora se justifique por quadro alérgico congênito, acentuado pelo hábito de fumar, concluindo o laudo pericial que ela estava exposta por longo lapso de tempo aos diversos fatores agressivos decorrentes da atividade poluidora da empresa, que contribuíram efetivamente para o desencadeamento, ou agravamento da patologia diagnosticada, presentes os pressupostos da responsabilidade civil e decorrente obrigação de
} 
Ainda, a ausência de parâmetros entre probabilidade/improbabilidade pode remeterse a bloqueios dos processos decisionais, como a tautologia. Entretanto, pode-se ressaltar que o Direito pátrio aplica o princípio do livre convencimento do juiz, sem critérios taxativos. Nesse norte, a avaliação da probabilidade nas decisões juridicas ficará a cargo da proporcionalidade e do bom-senso do julgador.

\section{CONCLUSÃO}

Inegável que as embalagens plásticas são benéficas para o cotidiano humano, uma vez que consideradas opções práticas e econômicas para o armazenamento e transporte das mais variadas espécies de produtos. O embalamento é essencial para a integridade de qualquer produto, seja ele orgânico ou inorgânico. Além disso, são relevantes para a economia global, pois movimentam bilhões ao ano e geram milhares de empregos.

Por outro lado, apresentam uma face sombria que submete o homem e o meio ambiente a riscos invisíveis, pois as embalagens possuem componentes químicos que colocados em contato com os alimentos podem ocasionar danos à saúde humana. Os estudos científicos sobre esse tema não são definitivos, motivo pelo qual são dotados de incertezas científicas para um processo decisional. Mesmo assim, o judiciário terá que decidir acerca desses riscos diante da ação civil pública movida pelo Ministério Público Federal contra a ANVISA. Há a incerteza cientifica quanto os riscos do Bisfenol A - BPA nas embalagens plásticas, como também não há interesses comerciais na promoção da informação do risco aos consumidores.

A pesquisa realizada tratou do assunto através da perspectiva luhmanniana do risco, pois a característica no setor produtivo dos materiais plásticos é um tanto complexa e contingente. Tem-se que a concepção de risco passa a ser essencial à evolução social, tendo em vista que parte da ideia de que tudo que pertence à sociedade está predisposto ao risco.

Em resposta aos problemas apresentados para a pesquisa, pode-se afirmar que os riscos integram os sistemas sociais, sendo as incertezas e as inseguranças uma realidade a ser

indenizar. Sentença mantida. Apelo desprovido. (Apelação Cível No 70000932830, Nona Câmara Cível, Tribunal de Justiça do RS, Relator: Ana Lúcia Carvalho Pinto Vieira. Julgado em 27/11/2002). Do corpo do acórdão extrai-se: Não há dúvida de que, embora os aspectos sopesados pela r. sentença - quadro alérgico congênito e maior fonte geradora em virtude de a apelada ser fumante - a emissão de agentes poluentes por parte da ré contribuiu, pelo menos disso há forte probabilidade, para o acirramento da sensibilização da autora. 
enfrentada também pelo sistema do Direito. Para tanto, torna-se necessário realizar uma adequação entre decisões jurídicas e as noções de risco, rompendo-se com os ideais de segurança e certezas. Com isso, o sistema deve realizar uma leitura da decisão, levando-se em conta a complexa função preventiva ou precaucional que passa a assumir.

Nessa ótica, o presente trabalho demonstrou a possibilidade de um caminho interpretativo para reduzir a complexidade das incertezas científicas através da Teoria das Probabilidades que vem sendo discutida no âmbito do Direito Ambiental, que revela, com destaque, a consciência do risco no processo de decisão, a tal ponto que interliga a complexidade dos riscos de danos aos efeitos difusos e futuros.

A adoção da probabilidade é pertinente, mas a ausência de critérios de aferição dos graus de probabilidade pode aumentar a complexidade do processo decisional. Na pesquisa, o resultado acerca da avaliação da probabilidade nas decisões juridicas repousa em critérios de proporcionalidade e do bom-senso do julgador, que de um lado torna possível a avaliação sustentavel do tema, e de outro, corre-se o risco da arbitrariedade.

\section{Referências Bibliográficas}

ANVISA. Resolução - RDC n 91, de 11 de maio de 2001. Aprova o Regulamento Técnico Critérios Gerais e Classificação de Materiais para Embalagens e Equipamentos em Contato com Alimentos constante do Anexo desta Resolução. <Disponível em: http://s.anvisa.gov.br/wps/s/r/yAc>. Acesso em 12 de janeiro de 2016.

BARROS, Hilda Duval. Estudo da exposição do consumidor aos plastificantes ftalato e adipato de di-(2-etil-hexila) adicionados a filmes de PVC, utilizados para acondicionamento de alimentos gordurosos. 80f. Tese (Doutorado em Vigilância Sanitária). Programa de pósgraduação em vigilância sanitária instituto nacional de controle de qualidade em saúde Fundação Oswaldo Cruz. Rio de Janeiro: INCQS /FIOCRUZ, 2010. p. 19. Disponível em: http://www.arca.fiocruz.br/xmlui/bitstream/handle/ icict8243/61.pdf?sequence=2. Acesso em 10 de março de 2016.

BRANCO, Samuel Mulgel. Ecossistêmica: uma abordagem integrada dos problemas do meio ambiente. 2 ed. São Paulo: E. Blücher, 1999.

BRASIL. Lei 9782/99, de 26 de janeiro de 1999. Define o Sistema Nacional de Vigilância Sanitária, cria a Agência Nacional de Vigilância Sanitária, e dá outras providências. <Disponível em: http://www.planalto.gov.br/ccivil_03/leis/L9782.htm>. Acesso em: $10 \mathrm{de}$ janeiro de 2016.

CARVALHO, Délton Winter de. Dano ambiental futuro: a responsabilização civil pelo risco ambiental. $2^{\mathrm{a}}$ ed. Porto Alegre: Livraria do advogado Editora, 2013. 
DÍEZ-PICAZO, Luis. Fundamentos del derecho civil patrimonial. 5 ed. v.2. Madrid: Civitas, 1996.

GRINOVER, Ada Pellegrini. A tutela dos interesses difusos. São Paulo: Max Limonad, 1984.

LEITE, José Rubens Morato; AYALA, Patryck de Araújo. Direito Ambiental na sociedade de risco. Rio de Janeiro: Forense, 2004.

; CARVALHO, Délton Winter de Carvalho. O nexo de causalidade na responsabilidade civil por danos ambientais. Revista de Direito Ambiental. São Paulo: RT, ano 12, n. 47, 2007.

LUHMANN, Niklas. Sociologia do Direito 1. Trad. de Gustavo Bayer. Rio de Janeiro: Edições Tempo Brasileiro, 1983.

Sociologia del riesgo. México: Iberoamericana, 1992.

Das Paradox der Menschenrechte und drei Formen seiner Entfaltung,

Soziologische Aufklärung 6, Westdeutscher Verlag, Opladen 1995, S. 229-236. (Trad. de Ricardo Henrique Arruda de Paula e Paulo Antônio de Menezes Albuquerque. Themis, Fortaleza, v. 3, n. 1, p. 153 - 161, 2000).

Legitimação pelo Procedimento. Tradução de Maria da Conceição,

Brasília: UNB, 1980.

MAGRINI, Alessandra [et al]. Impactos ambientais causados pelos plásticos: uma discussão abrangente sobre mitos e dados científicos. Rio de Janeiro: E-Papers, 2012.

MIRRA, Álvaro Luiz Valery. Direito Ambiental: o princípio da precaução e a sua aplicação judicial. Revista de Direito Ambiental. São Paulo: RT, p. 92-103. n. 21, ano 6, jan/mar/2001.

PLASTICS EUROPE Association of Plastics Manufactures. Plastics - the Facts 2015: an analysis of European plastics production, demand and waste data. Belgium, 2015. Disponível em: http://www.plasticseurope.org/documents/document/20151216062602-plastics_the_facts _015_final_30pages_14122015.pdf. Acesso em 20 de dezembro de 2015.

REGAÑON, Calixto Díaz. ALCALÁ, Garcia. Relación de causalidad e imputación objetiva en la responsabilidad civil sanitária. Barcelona: InDret. n. 180, 2003. Disponível em: http://www.indret.com. Acesso em: 03 mar. 2009.

ROCHA, Leonel Severo. Introdução à teoria do sistema autopoiético do direito. 2 ed. Porto Alegre: Livraria do Advogado, 2013.

Juruá, 2012.

e DUARTE, Francisco (coords.). A construção sociojurídica do tempo. Curitiba:

ROCHA, Leonel Severo. Introdução à teoria do sistema autopoiético do direito. 2 ed. Porto Alegre: Livraria do Advogado, 2013. 
SELKE. S. E. M. Plastic in Packaging. IN: ANDRADY, A. L. Plastic and the Environment. New Jersey: John Wiley \& Sons, 2003.

SIMIONI, Rafael. O que a decisão jurídica observa? Contribuições da teoria dos sistemas de Niklas Luhmann às teorias pós-positivistas da decisão jurídica. IN: Juridicização das esferas sociais e fragmentação do direito na sociedade contemporânea. SCHWARTZ, Germano (Org.). Porto Alegre: Livraria do Advogado, 2012.

TEUBNER, Gunther. Direito, sistema e policontexturalidade. Piracicaba: Unimep. 2005. 